\title{
Impetus on Big Data to Boost Indian MSME Sector and Economy using Cloud Storage
}

\author{
Aparajita Dixit \\ Dept. of Computer Science and \\ Technology \\ Research Scholar, Rajasthan \\ Technical University, Kota
}

\author{
Suresh Kumar Sharma \\ Assistant Professor, Computer \\ Science, SKN College of \\ Agriculture, Jobner and \\ Research Scholar, RTU, Kota
}

\author{
Durga Prasad Sharma, PhD \\ Dean Research, \\ RTU Research Centre at MAISM
}

\begin{abstract}
In the Indian economy, the major work force is contributed from rural areas where most of the population is involved in very small businesses and contributing a significant share to our society. Over a period of time these small businesses have become the driving force for the overall industrial development. The Micro, Small and Medium Scale Enterprises have not only contributed to improve the gross domestic product (GDP) of India but also lifted people from below poverty line. Of late big data has become a revolution, it has completely changed the way of decision making and implementing policies at both micro \& macro level of Indian economy. The emphasis of this paper is on why and how to exploit big data in micro, small and medium scale enterprises (MSMEs) by describing storage aspects of SME and MSME data on cloud for better access to filtered data efficiency of data access. The power of big data and business analytics which can be leveraged by small and medium size enterprises as well as MSME. [1]
\end{abstract}

\section{Keywords}

MSME, SME, Big data, Indian Economy, GDP, development, cloud data storage, innovativeness and opportunities

\section{INTRODUCTION}

The Micro, Small and Medium Scale Enterprises (MSMEs') in India is the bedrock of Indian economy. MSMEs contribute to economic and social development by providing employment opportunities to the people of India at every nook and corner. As per Fiscal year 2018, MSMEs lending of over Rs 15 trillion, accounted for around $22 \%$ of corporate lending in India. Big data has transformed Indian economy and has become critical to Indian economy. It is nurturing new businesses and jobs as well as creating opportunities in different areas. [3]. The MSME have now accepted all over the world as the main source of economic growth and development. Moreover, as many people are involved in [28]

MSME's sector, there is no doubt that these businesses have power to propel our nation altogether to new heights. [4]

Therefore, it is certain to say that MSME's are powering a silent revolution in India. [4]

Big data is administered by high volume, high speed, high assortment, and high intricacy. In the present constantly associated world, countless sensors over different applications persistently create floods of information for assessment. Mechanized procedures gather this for all intents and purposes boundless information from different sources in various arrangements actions which make helpful to MSME companies for business informative decisions. [2].

Big data huge information and investigation can be used to drive choices for different parts of an organization, for example, enrollments, business leads, valuing, and following rivalry, to name a few. Since the volumes of information taken care into the framework can get overpowering, it is vital to comprehend the utility of this information with the goal that greatest worth can be produced. [6].

\subsection{Adoption of big data analytics}

Information is regarded as an asset in the present dynamic world and is being increased in volume like never before. All multinationals are spending hefty amount in research and development work associated with data to get the filtered and customized information. The usage of enormous information and analytics innovations are modifying the way organizations across the globe are undertaking work. There is an immediate prerequisite for SMEs to think on Big information reception to address their voluminous information challenges. [30]

\subsection{Growth and performance}

In recent years the MSME sector has recognized high growth rate as compared to other industrial sectors. In last 4 years plan the $13 \%$ growth rate of overall performance is in industrial sectors. [12].

\section{ROLE OF MSMES IN INDIAN ECONOMY}

MSME's Contribution to Society: MSMEs contribute around $24.63 \%$ of the GDP from service activities and $6.11 \%$ of the manufacturing GDP. MSME ministry has set a target to up its contribution to GDP to $50 \%$ by 2025 as India becomes a $\$ 5$ trillion economy. [4]

Table 1: Activity wise approximate number of MSME's

\begin{tabular}{|c|c|c|c|c|}
\hline \multirow{2}{*}{$\begin{array}{c}\text { Activity } \\
\text { Category }\end{array}$} & \multicolumn{3}{|c|}{$\begin{array}{c}\text { Estimated Number of } \\
\text { Enterprises (in lakh) }\end{array}$} & \multirow{2}{*}{$\begin{array}{c}\text { Share } \\
(\%)\end{array}$} \\
\cline { 2 - 4 } & Rural & Urban & Total & \\
\hline$(1)$ & $(2)$ & $(3)$ & $(4)$ & $(5)$ \\
\hline Manufacturing & 114.14 & 82.50 & 196.65 & 31 \\
\hline Trade & 108.71 & 121.64 & 230.35 & 36 \\
\hline Other Services & 102.00 & 104.85 & 206.85 & 33 \\
\hline Electricity* & 0.03 & 0.01 & 0.03 & 0 \\
\hline All & $\mathbf{3 2 4 . 8 8}$ & $\mathbf{3 0 9 . 0 0}$ & $\mathbf{6 3 3 . 8 8}$ & $\mathbf{1 0 0}$ \\
\hline
\end{tabular}


- Exports: It contributes around $45 \%$ of the overall exports from India.

- Inclusive growth: MSMEs contribute in advancing inclusive growth by providing opportunities in villages, tier II and tier III cities. For example: Khadi and Village industries require low per capita investment and employs a large number of women in villages, tier II and tier III cities.

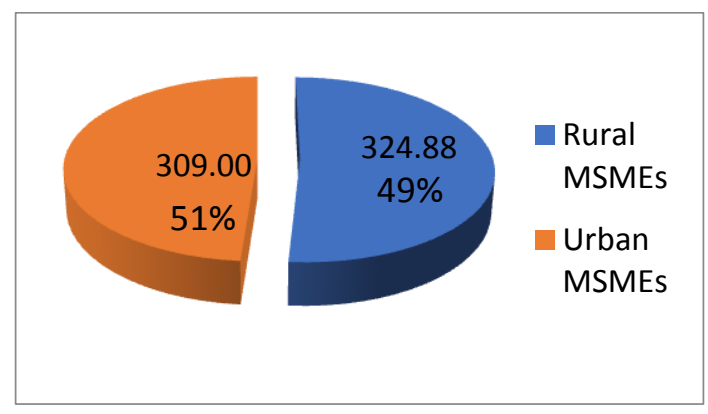

Figure 1: Percentage share of Rural and Urban MSMEs in the country (number in lakhs)

- Job Opportunities: After agriculture, MSMEs are proving highest employment to Indian society.

- Promoting new ideas: It gives opportunity to potential entrepreneurs to explore and implement new business ideas.

- Financial inclusion: Small businesses and industries in villages and tier-II, tier-III cities provide opportunities for people to use formal banking services.

\subsection{Downward trend in Indian MSME:}

The contribution of MSME's in India's GDP has decreased in terms of percentage over the period of time and as per Central Statistics Office (CSO), Ministry of Statistics \& Program, the share of MSME in India's GDP as shown below:

Table 2: Share of MSME in India's GDP.

\begin{tabular}{|c|c|c|c|c|c|c|}
\hline \multicolumn{7}{|c|}{ (Figures in Rs. Crores adjusted for FISIM at current prices) } \\
\hline$\stackrel{\grave{\Xi}}{\grave{\Xi}}$ & 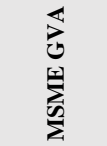 & 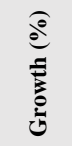 & 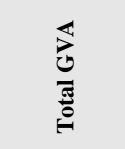 & 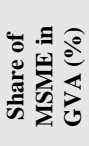 & $\begin{array}{l}\text { जิ } \\
\text { हैँ } \\
\text { है }\end{array}$ & 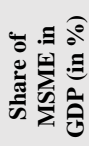 \\
\hline $\begin{array}{c}2011 \\
-12\end{array}$ & 2622574 & - & 8106946 & 32.35 & 8736329 & 30.00 \\
\hline $\begin{array}{c}2012 \\
-13\end{array}$ & 3020528 & 15.17 & 9202692 & 32.82 & 9944013 & 30.40 \\
\hline $\begin{array}{c}2013 \\
-14\end{array}$ & 3389922 & 12.23 & 10363153 & 32.71 & 11233522 & 30.20 \\
\hline $\begin{array}{c}2014 \\
-15\end{array}$ & 3704956 & 9.29 & 11504279 & 32.21 & 12467959 & 29.70 \\
\hline $\begin{array}{c}2015 \\
-16 \\
\end{array}$ & 4025595 & 8.65 & 12566646 & 32.03 & 13764037 & 29.20 \\
\hline $\begin{array}{c}2016 \\
-17\end{array}$ & 4405753 & 9.44 & 13841591 & 31.83 & 15253714 & 28.90 \\
\hline
\end{tabular}

\subsection{Problem areas of MSME`s in India}

In present time, Indian MSME's are encountering many problems. These problems are of different type and are dynamic in nature. Most of the problems are controllable but few are uncontrollable too. Considering data analysis and detailed study of the related literature the MSME'S problems can be explained as follows: - [10]

- Unavailability of funds from financial institutionsAs the process of getting loan approved from banks is very complicated and lengthy which requires a lot of paper work. Therefore, the general public is unable in taking credit from bank. [12]

- Competition from large scale companies- These days established companies which are of large scale in nature are proving good and quality services at very low price. Therefore, it is becoming difficult for MSME's to compete with such strong players in same market. [13]

- Lack of expertise- MSMEs people are not updated with recent trends and technologies. Therefore, there procedures for production of goods and products are outdated and hence cannot be compared with what multinational companies are proving in affordable rates. [9].

\subsection{Ways to improve the contribution of MSME's in India's GDP by using Big} Data.

- Availability of Technologies:

Big data can be used to make different technologies available which MSME people might require. These lists of technologies should be easily available to workers and should be simple so that they can use it and get benefited.

- Access to proven guidelines:

Many people may not be aware of different methods/steps for their startups. Big data can be used for providing relevant and authenticated information by the mean of data analysis for different MSME's sector and should make it available for common people to utilize it. [32]

- Knowledge Centers

Big data can be used to collect sufficient information which MSME's people need. Government should provide different training programs for awareness of people. [29]

- Dedicated financial body for MSME's:

There should be availability of some financial institutions which can provide required funds to budding entrepreneurs in cheaper rates.

\section{RELATED WORK}

1. Lawal, et al [1]. Opines there is no all-inclusive meaning of little scope industry. Definition too changes extra amounts of time, inferable from changes in value level, propels in innovation and different contemplations. Standards that might be utilized in the meaning of little scope enterprises (SSEs) regularly incorporate turnover, net yield and work. These elements are normally utilized in light of the fact that they are practical and simple to gauge.

2. Margaret rouse et al [2]. SME is a suitable term for slicing other organizations and businesses that are somewhere between the "small office-home office" 
(SOHO) size and the larger enterprise. According to the European Union has defined an SME as a legally independent company with not more than 500 employees. SMEs are very heterogeneous groups. SMEs are found in a widely from the single artisan producing horticultural actualizes for the town and market.

3. Jones et.al [3]. Proposed that, paying little heed to the volume of an organization, large information is a reference to informational indexes as well as complex and huge for organizations to oversee inside their customary IT systems. But a look past the specialized language will uncover that huge information is about opportunity. The chance to gain from an organization's information so as to make more intelligent business decisions. While it might shock no one that enormous endeavor organizations are taking preferred position of the open door that huge information bears, a few business visionaries may not realize that private companies can do likewise.

4. Yue, F. \& Ma, L. et.al [4]. Large information has now become a well-known term used to depict the exponential development and accessibility of information both organized and unstructured. As of late, large information apparently is as essential to business and society as the web has become. More information may prompt progressively precise investigations. Increasingly exact investigations may prompt progressively certain dynamic.
5. Ms. Subina Syal et.al [5] the author said that the MSME is final part and gate way of global growth on the strength of power product range. the industries are considered for MSME two categories. 1. Production inductris.2. Services industries.

6. Ogbuokiri, B.O. et.al [6] In this paper author represent the implementation of big data for small and medium enterprise for better performance of data access method using cloud data storage.

\section{RESEARCH METHODOLGY AND PROPOSED WORK}

In this paper, it is proposed that work based on cloud storage of MSME companies. The implementation of big data for getting better results by enabling businesses to take informed decisions. The following characteristics are taken by big data implementation for SME and MSME sectors. [8]

1. Simple 2. Cost Effective. 3. Flexibility \& choices; The big data adoption for business analytics to provide solution for MSME and SME companies. The big data woks as technical input in the form of data, using for business decisions. The proposed methods are given below:

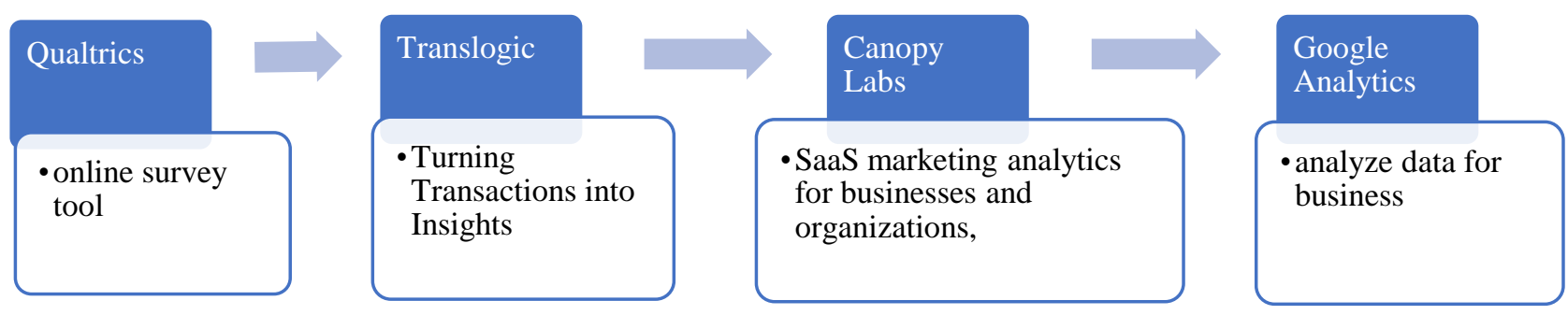

Figure 2: Research Methodology

1. Qualtrics - online survey tool that allows one to build, distribute surveys and analyze responses, 2. Tranzlogic Turning Transactions into Insights, 3. Canopy Labs - SaaS marketing analytics for businesses and organizations, 4. Google

Analytics - analyze data for business in one place to make smarter decisions.

Big data and analytics can be flourish to drive decisions for various aspects of a company, such as business leads, recruitments, tracking competition and pricing to name a few. Since the volume of data fed into the system can get overpowering, it is key to understand the utility of this data so that maximum value can be generatedCloud Computing has now moved past the fundamental and conventional services of email and data storage, backup, and document sharing and will be implemented as:

- Big data implementation-based cloud data store architecture used for SME and MSME companies.

- Migration to cloud data storage with Business Intelligence as a service model with managed services.

- Establish strong governance and build self-service capabilities into the process for business informatics.

- Leverage a partner to utilize the optimal blend of people, process, and technology

- Get started with a pre-built lending library of best practice reports and dashboards and virtual data access. 
India Indigo: Domestic: Passengers Carried

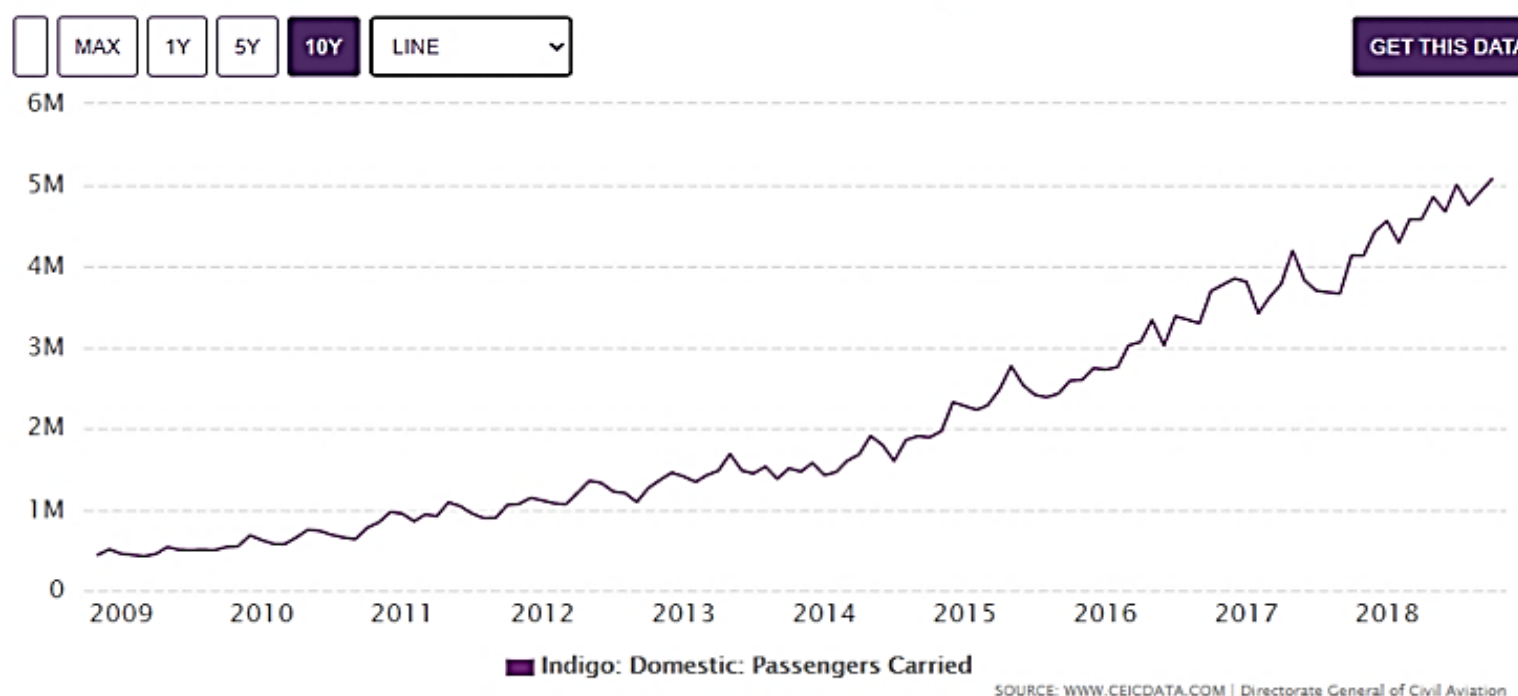

Figure 3: Indigo Domestic Passengers Carries (source: www. CEICDATA.COM - Directorate General of Civil Aviation)

Big data analytics perform on the basis of cloud data storage. Cloud architecture will perform optimization of data storage and global access.

The cloud data storage performs by open track framework model using JAVA platform. It will show the virtual impact of data access, cost reduction, optimization model performed. The framework represents the various model to perform better data storage over cloud architecture along with data center. [14]

For this implementation tactics, software aspects for data storage optimization and for global access has been used. The big data analytics for SME and MSME are performing for various companies like Amazon, Flipkart, Myntra, Indigo Airlines, Spice Jet and other retail market \& online Ecommerce platform [12].

\section{CASE STUDIES:}

\subsection{INDIGO AIRLINES}

Indigo is India's largest passenger airline with a market share of $48.2 \%$ as of September, 2019. It primarily operates in India's domestic air travel market as a low-cost carrier and also internationally. IndiGo has become the first choice of Indians because of its on-time performance, convenient timings, new sectors/routes and cheaper fare in comparison to other airlines.
The reasons for outstanding performance of IndiGo are as follows:

- IndiGo has set the golden standard when it comes to applying big data for flight recommendations which includes seat, meal and timings recommendations based on past searches on its and other platforms like Make My Trip, Yatra, Trip advisor, goibibo etc. by the use of predictive analytics, Indigo is successfully able to accurately predict where, when at what time the passengers are likely to fly next.

- IndiGo is using another application of big data i.e. Demand forecasting in which it predicts the demand of passengers on the basis of time and season. It increases number of flights to Srinagar, Leh and other popular hill stations. It also starts flying to uncommon routes like Dharamshala, McLeod Ganj in summer season only.

- As a proof of how Indigo is benefitted by using big data in data findings, data analysis, data collection, data filtration etc. here are the graphs of last ten years showing the growth of Indigo and making it the first choice of Indian passengers. 
View India's Indigo: Domestic: Number of Flight from Aug 2006 to Oct 2018 in the chart:

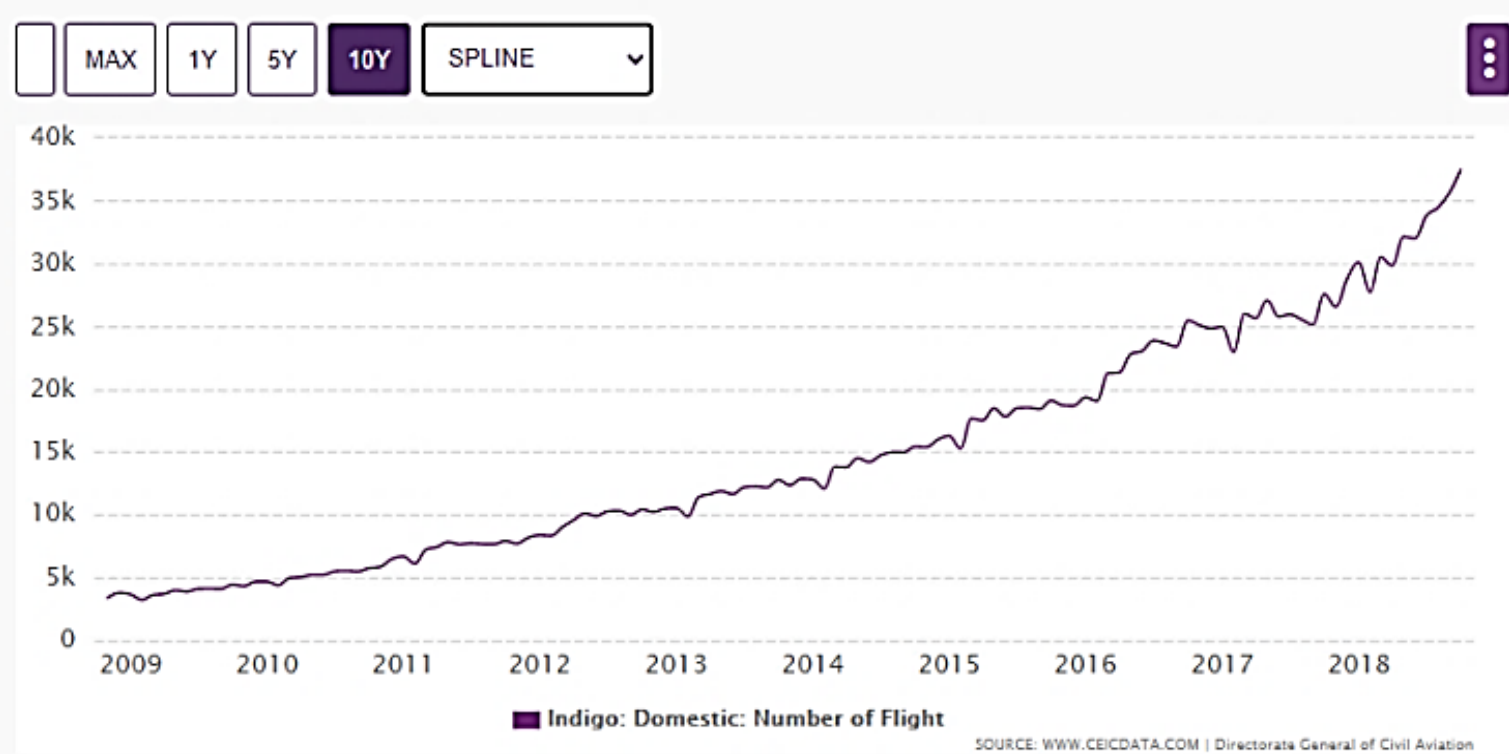

Figure4: Indigo - Number of flight (Source CEICDATA.COM - Directorate General of Civil Aviation)

\subsection{PATANJALI}

Patanjali is one of the fastest growing companies in India. It started in the year 2006 with limited items and now it is selling numerous products and promoted usage of natural and organic items. The company used data analytics and studied the comparison of MSME sector with the overall industry as shown in figure 5 for advertisement, food preferences, Individual's requirement to study the market and captured it by spreading health awareness and labeling the items with Swadeshi tag. The revenue generated by Patanjali has increased manifold in last four years by using data analytics to gain the competitive advantage. The figure 6 below shows the growth in revenue. [26]

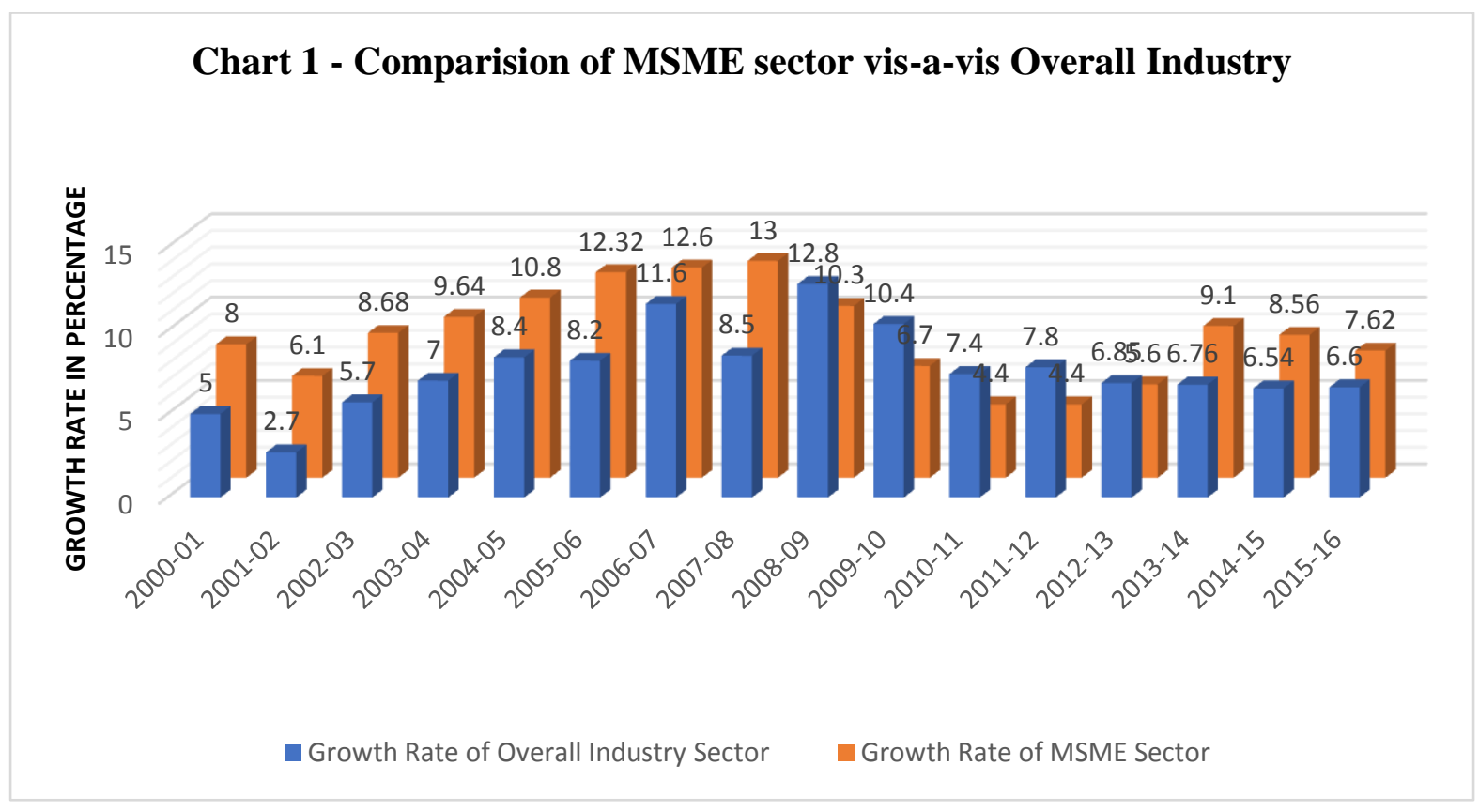

Figure 5: Comparison of MSME Sector with overall Industry (Source Annual Reports of Ministry of MSME) 


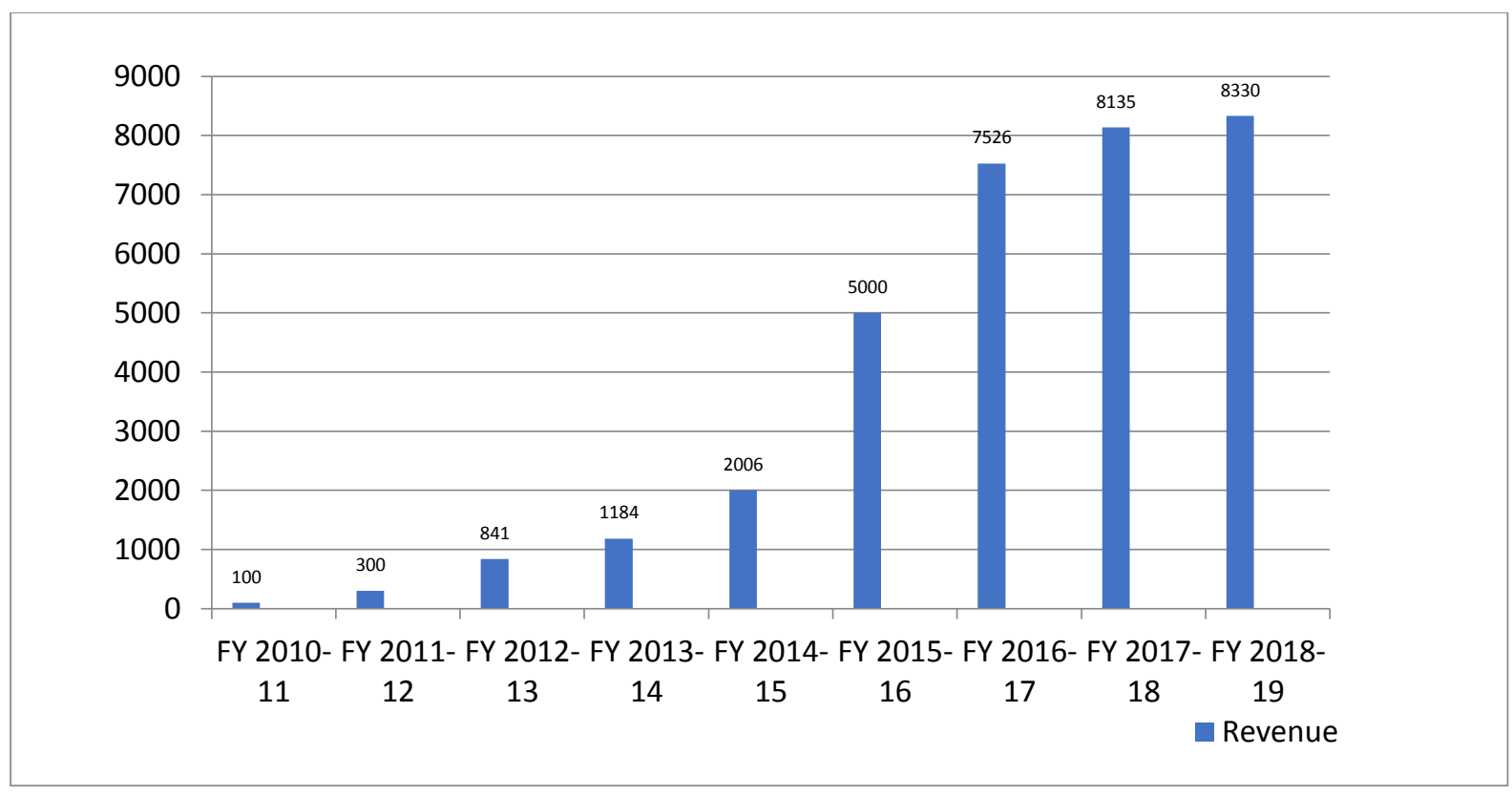

Figure 6: Revenue Generated by Patanjali

\subsection{KRISHI JAGRAN - MAGAZINE}

Krishi Jagran, an Indian Micro enterprise which lead to developing an environment of agricultural magazine in India. It analyzed the data beautifully and accumulated information which was provided to farmers for better decision making and gradually started publishing in many languages and in present it publishes the magazine in 12 Indian languages. Which makes it unique and enables to capture wide geographical area by providing insight to scientists, farmers, businesses and other associated sectors to make the rural India self-reliant. The company started with a noble idea of providing critical information and new ideas related with agriculture and became widely circulated agri-rural magazine in India and won The LIMCA Book of Records and in the year 2019 Krishi Jagran was also felicitated by ministry of MSME, govt. of India. [27]

The growth rate of MSME as compared to growth rate of overall Industry sector has been found dominating over the years, hence playing a key role in overall growth of industries.

\section{CONCLUSION}

Big data analytics has become the most vital element for almost all of the organizations today. The right use of big data helps the entrepreneur in making right decision in right time.

This paper highlights how small and medium scale enterprises can extract the most from the big data i.e. cost reduction, competitive advantage, making correct information available to entrepreneurs, better decision making due to availability of correct and timely information, proven guidelines, do's and don'ts etc. The way Indigo transformed itself using big data analytics from an entrant in Indian aviation into the sector leader, The Patanjali evolved from selling limited items to wide range of items and Krishi Jagran Magazine progressed from one language to 12 languages including online subscriptions and became the highest selling agri-rural magazine in India. Similarly, MSME's can also use big data analytics over cloud to propel their growth rate and to gain the competitive advantages. It is recommended that Indian government may consider using big data analytics in MSME's and provide filtered information to people through government service centers and they should also regularly update data on website as well as on its app.

Conventional approach, it still has several shortcomings.

\section{FUTURE SCOPES}

In this paper, the MSME sector of India is today, at the portal of worldwide development on the extension of quality items. Notwithstanding, help from the Government is required to limit the exchange expenses of innovation upgradation, showcase entrance, modernization of framework and so on. In this paper a look at development of Indian Micro Small and Medium Scale Enterprise Sector in the course of the most recent ten years has been looked. The future scope for designing dashboard and latest platform like supply chain logistics and block chain implement for data storage for better aspects. For research point of view the impact of decentralized data base concept will also introduce for MSME and SME growth aspect. Block chain is considered as future study topic for upcoming scholars.

\section{REFERENCES}

[1] Lawal, A. A. And Bello, M.A. (2010) Business Policy and Strategic Management. Lagos. Suhani Nigerian Enterprises.

[2] Margaret Rouse (2011) small to medium enterprise (SME), Business intelligence - www.goindigo.in

[3] Annual report of Ministry of Statistics Programme Implementation-2018.

[4] Southard jones (2014) Retrieved from http://www.entrepreneur.com/article/235338.

[5] Sonia Buchholtz, MaciejBukowski, Aleksander Śniegocki(2014).

[6] Gabriella Catteneo (2014), The European Data Market, IDC presentation given at the NESSI summit in Brussels 
on 27 May 2014, available online at: http://www.nessieurope.eu/?Page=nessi_summit_2014

[7] Andrew SsegawaKiggundu (2013), How can Big Data benefit SME's in developing African Countries?, MSc. Thesis, Univesit y of Botswana.

[8] Safiriyu, Adijat Morenikeji and Njogo, Bibiana Oluchukwu (2012), Impact of small and medium scale enterprises in the Generation of Employment in Lagos state, Kuwait Chapter of Arabian Journal of Business and Management Review Vol. 1, No.11; July 2012.

[9] Organisation for Economic Co-Operation and Development (OECD) (2004).OECD Principles of Corporate Governance. Available OECD Publications Service, Paris Cedex 16, France.

[10] Ayyagari, Meghana and Demirgüç-Kunt, Asli and Beck, Thorsten (2003), Small and Medium Enterprises across the Globe: A New Database. World Bank Policy Research Working Paper No. 3127. Available at SSRN: http://ssrn.com/abstract=636547.

[11] Annual Reports, Ministry of Small-Scale Industries, Government of India.

[12] "Micro, Small and Medium Enterprises Development Act - Background Paper", Jessica Wade, Small Enterprise Finance Centre, IFMR.

[13] "Ministry of Micro, Small \& Medium Enterprises, 2007: Micro, Small and Medium Enterprises in India: An Overview", Ministry of Micro Small and Medium Enterprise, Government of India.

[14] MSME Development Act 2006, Ministry of MSME, Government of India.

[15] "Final Results: Third All India Census of Small-Scale Industries 2001-2002”, August 2004 Edition, Ministry of Small-Scale Industries, Government of India.

[16] Venkatesh, S. and Muthiah, K. (2012), „SMEs in India: Importance and Contribution ${ }^{\text {ee }}$, Asian Journal of Management Research, Vol. 2, No. 2.

[17] Subramanyam, P., Reddy, B. R. (2012). Micro, small and medium enterprises in India: An overview. VSRD International Journal of Business and Management Research, II (XI), 532-539.

[18] Singh, R., Verma, O.P., and Anjum, B. (2012), „Small Scale Industry: An Engine of Growthe, Zenith International Journal of Business Economics \& Management Research, Vol.2 Issue 5. Online available at http://www.zenithresearch.org.in.

[19] Sandesara, J.C. (1993) "Modern Small Industry, 1972 and 1987- 88: Aspects of Growth and Structural Change." Economic and Political Weekly, Vol.28 No. 6.

[20] Dixit, A. and Pandey, A.K. (2011), „SMEs and
Economic Growth in India: Co integration Analysise, The IUP Journal of Financial Economics, Vol. IX, No. 2, PP. 41-59.

[21] Bargal, H., Dashmishra, M., and Sharma, A. (2009), „Performance Analysis of Small-Scale Industries - A Study of Pre-liberalization and Post-liberalization period "e, International Journal of Business and Management, Vol 1, No 2.

[22] Bhavani, T.A. (2011), "Dynamic Business Environments: What These Mean for Indian Small Enterprises" in "Micro and Small Enterprises in India: Era of Reforms: Keshab Das (Ed)" pp. 27-45.

[23] Christopher J. Green Colin H. Kirkpatrick, and Victor Murinde, (2006) Finance for Small Enterprise Growth and Poverty Reduction in Developing Countries Journal of International Development J. Int. Dev. 181017-1030 (2006) Published online in Wiley Inter Science. (www.interscience.wiley.com).

[24] Khurud B.S. (2015). Export performance of MSME sector in the post liberalization era. International Journal of Economic and Business Review, Vol.3 Issue1.

[25] Aarti Deveshwar (2014). Globalization: Impact on Indian Small and Medium Enterprises. The Business and Management Review, Vol.5 No.3

[26] https://www.forbes.com/profile/acharyabalkrishna/\#ec9c5f21d993

[27] https://www.downtoearth.org.in/blog/agriculture/howbig-data-can-boost-agricultural-growth-65932

[28] Arvind Kumar Sharma, Sharma DP (2010), Selection, implementation \& support of sap ERP system approach in manufacturing industry. Global Digital Business Review, Vol. 4, No. 1, 2010

[29] D Yadav, B Keswani (2017), Porting Intranet Over Cloud for Educational Service Amplification (Special Reference to Higher Educational Institutions), SCOPUS Sylwan Journal Europe 161 (8)

[30] DP Sharma (2015), Mobile Agent-Based Authentication: A Model for User Authentication in a Distributed System, International Journal of Computer Applications 112 (13)

[31] DP Sharma (2012), The Best performance practices in project management of SAP ERP accomplishment, International Journal of Information and Electronics Engineering-Singapore

[32] DP Sharma, RK Sharma, An Ayodele J (2008), Convergence of Intranetware in Project Management for Effective Enterprise Management, Journal of Global Information Technology (JGIT)-USA 4 (2), 65-85.

[33] CEICDATA.COM - Directorate General of Civil Aviation). 